\title{
INTRAORAL SPREAD OF STREPTOCOCCUS MUTANS IN MAN
}

\author{
Mona L. SVANBerg* and W. J. Loesche \\ Dental Research Institute, University of Michigan, School of Dentistry, \\ Ann Arbor, MI 48109, U.S.A.
}

\begin{abstract}
Summary-Streptomycin-resistant strains of Streptococcus mutans were reliably established in 3 subjects by the use of artifical fissures (AF) containing adherent growth of the Strep. mutans strain. The intraoral spread of these implanted Strep. mutans strains was monitored in the subjects while the AF was in situ and for up to 26 weeks after the AF was removed. During the 26 weeks, all tooth surfaces and saliva were repeatedly sampled. The implanted Strep. mutans spread to adjacent and antagonistic teeth only on the side of the dentition where the implantations were made. After establishment of a streptomycin-resistant strain in one subject, a sterile AF was inserted multiple times in the same occlusal surface, on which the implantations had previously been made. The sterile AF was colonized by local spread of Strep. mutans strains, as was shown by the relationship between the percentage of streptomycinresistant Strep. mutans to total Strep. mutans colony forming units (CFU) counts in the AF and the salivary flora. The streptomycin-resistant Strep. mutans represented 10.5-93.5 per cent of the total Strep. mutans CFUs in the AF, but only 0-1.5 per cent of the Strep. mutans CFUs in the saliva during colonization of the AF. The intraoral establishment and spread of the implanted Strep. mutans seemed favoured by conditions present in subjects with high salivary concentrations of endogenous Strep. mutans strains and high caries experience, as expressed by the high number of filled tooth surfaces.
\end{abstract}

\section{INTRODUCTION}

The cariogenic potential of Streptococcus mutans has been clearly demonstrated in animal models (Keyes, 1962,1968 ) and some role for this microorganism in dental caries in man seems evident (Krasse et al., 1968; Loesche et al., 1975).

Several attempts have been made to study the intraoral ecology of Strep. mutans by the implantation in the human mouth of Strep. mutans strains containing, for identification purposes, a streptomycin-resistant marker (Krasse et al., 1967; Jordan et al., 1972; Edman et al., 1975; Svanberg and Loesche, 1978), but most labelled strains were quickly eliminated from the mouth. Edman et al. (1975) established labelled strains in approximal sites on one side of the mouth in two volunteers and noted that the implanted strains were mainly recovered from that side. The artificial fissure model (Löe, Karring and Theilade, 1973) can be used to reliably implant streptomycinresistant strains in single occlusal sites (Svanberg and Loesche, 1978).

\section{Subjects}

\section{MATERIALS AND METHODS}

The three subjects $(G, T$ and $S)$ who participated had 38, 52 and 78 filled tooth surfaces, respectively, no carious lesions and no missing teeth. Subjects $G$ and $S$ had a normal occlusion and subject $T$ had a class III malocclusion.

An artificial fissure (AF) containing a Strep. mutans strain which had been made resistant to $1 \mathrm{mg} / \mathrm{ml}$ of

* Present address : Göteborgs universitet, Odontologiska kliniken, Fack 400, 33 Göteborg 33, Sweden. streptomycin was placed in a molar tooth in each subject. The AFs had been cultured in vitro and contained at the time of insertion $10^{7}$ colony-forming units (CFU) of Strep. mutans as adherent growth on the AF (Svanberg and Loesche, 1978). The AFs were each inserted three times in the occlusal surface of an upper first molar in subject $G$ and in a lower first molar in subjects $\mathbf{T}$ and $\mathrm{S}$. The implanted Strep. mutans strains $G, T$ and $S$ belonged to serotype $c$ and were re-introduced into the same mouth from which they originally had been isolated (Svanberg and Loesche, 1978)

\section{Bacterial samples}

The AFs containing strains $G, T$ and $S$ were left in vivo for 7-12 days. At 2, 4, 6, 8 and 26 weeks after removal of the infected $A F$, plaque samples were collected from all surfaces of all teeth in each subject. Twenty-six approximal tooth surfaces were sampled with dental floss and 56 smooth tooth surfaces with flattened hypodermic needles. Twenty-eight plique samples from margins of fillings and fissures were collected with 26-gauge hypodermic needles. The samples were taken in the morning after the subjects had refrained from all oral hygiene on the evening and morning before sampling. Two to four salivary samples were collected per weck during this 26-week period.

\section{Colonization of sterile $A F \mathrm{~s}$}

Strain $S$ established on the natural tooth surfaces in subject $S$ for a prolonged period of time. During this interval, stcrile AFs were inserted several times in the same tooth as that used earlier for the AF containing adherent growth of Strep. mutans. The 
sterile AF was left in situ for 1 and 2 days each on 2 occasions, for 5 days on 3 occasions and for 21 days on 1 occasion, whereafter the content of the AF was cultured. The bacterial samples were immediately placed in reduced transport fluid (RTF) (Syed and Loesche, 1972) and dispersed by sonification for $5 \mathrm{~s}$ (Branson model W 185 D, N.Y.).

\section{Bacteriological procedures}

The saliva and AF samples were serially diluted in $\mathbf{R T F}$, whereas the plaque samples from the tooth surface were placed in $2.5 \mathrm{ml}$ of RTF and not further diluted. $0.05-\mathrm{ml}$ aliquots from appropriate dilutions were spread on mitis-salivarius bacitracin agar (MSB) (Gold, Jordan and van Houte, 1973) and on MM10 sucrose agar (Syed and Loesche, 1973) with and without $0.2 \mathrm{mg} / \mathrm{ml}$ streptomycin. The inoculated plates were placed in an anaerobic chamber within $30 \mathrm{~min}$ of collection of samples and incubated at $37^{\circ} \mathrm{C}$ for $48 \mathrm{~h}$ in an atmosphere of 85 per cent $\mathrm{N}_{2}, 10$ per cent $\mathrm{H}_{2}$ and 5 per cent $\mathrm{CO}_{2}$.

Identification of colonies of Strep. mutans strains on the various media was based on their characteristic colonial morphology, supplemented if necessary with biochemical tests (Shklair and Keene, 1974), and by examination with fluorescent antibody directed against the various Strep. mutans serotypes (Grenier, Eveland and Loesche, 1973). The Strep. mutans counts were obtained from MSB agar and from MM10 sucrose agar. The counts of the streptomycin-resistant Strep. mutans were obtained from the MM10 sucrose agar with streptomycin. The counts of Strep. mutans on MM10 sucrose agar minus the counts of Strep. mutans on MM10 sucrose agar with streptomycin were considered to represent the counts of endogenous Strep. mutans. The total colony-forming unit counts (CFU) was obtained from the MM10 sucrose agar.

\section{RESULTS}

\section{Intraoral spread}

The AFs containing the streptomycin-labelled strains served to inoculate the other tooth surfaces while they were in vivo. After removal of these AFs, the streptomycin-resistant strains of Strep. mutans could be detected during the next 26 weeks on a vary-
Table 1. Persistence of streptomycin-resistant strains of Strep. mutans on tooth surfaces in volunteers

\begin{tabular}{lcrrrr}
\hline & \multicolumn{5}{c}{ Weeks after removal of } \\
& 2 & 4 & 6 & 8 & 26 \\
& & & & & \\
& $2 \dagger$ & 0 & 0 & 0 & 0 \\
Subject G & 10 & 6 & 7 & 8 & 0 \\
Subject T & 12 & 20 & 14 & 4 & 6 \\
Subject S & & & &
\end{tabular}

* Artificial fissure.

$\dagger$ Number of tooth surfaces with streptomycinresistant strains of Strep. mutans.

ing number of tooth surfaces (Table 1). In subject $\mathrm{G}$, two tooth surfaces were colonized at the 2 weeks sampling, but thereafter no streptomycin-resistant Strep. mutans could be detected. In subject T, 8 surfaces were colonized after 8 weeks and, in subject $S$, the implanted strain could be detected on 6 tooth surfaces 26 weeks after the removal of the AF. In subject $\mathrm{S}$, as many as 20 tooth surfaces had detectable streptomycin-resistant Strep. mutans 4 weeks after removal of the AF. The implanted strain spread to adjacent and antagonistic teeth only on the same side of the dentition as that on which the AF had been inserted (Figs. 1a-c). From 2 (subject G, Fig. 1a) to 26 (subject S, Fig. 1c) separate tooth surfaces were colonized at some time by the implanted Strep. mutans strains. In subject $\mathrm{T}$ (Fig. 1b), the spread to antagonistic teeth included both the maxillary premolars which, because of a class III malocclusion, were in occlusion with the mandibular molar that contained the AF. All tooth surfaces colonized by the implanted strain also contained detectable levels of endogenous Strep. mutans. In all subjects some surfaces which contained endogenous Strep. mutans did not become colonized by the implanted strain.

The implanted Strep. mutans strain G was detected in the salivary samples of subject $G$ for a longer period of time than in plaque samples, i.e. salivary samples were positive 8 weeks after removal of the AF, although the bacteria were found on the tooth surfaces only at the 2 week sampling (Table 2). Twenty-four consecutive salivary samples collected from subject $G$ from week 9 to week 14 were negative (a) Subject G
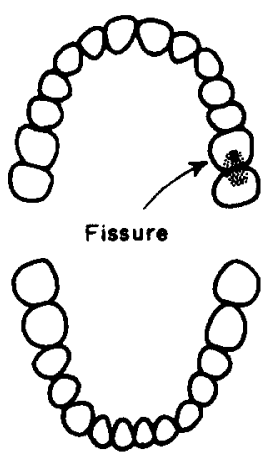

(b) Subject T.

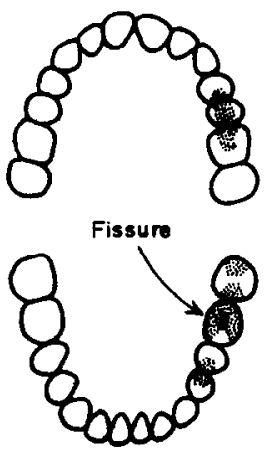

(c) Subject $\mathrm{S}$

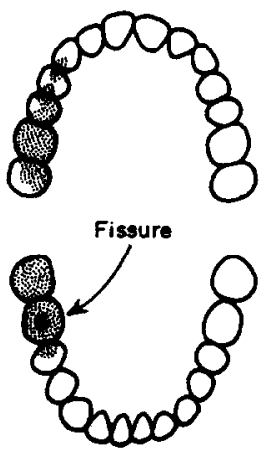

Figs. 1(a-c). Intraoral spread of implanted Strep. mutans in subjects G, T and S. Dotted fields, tooth surfaces colonized by implanted Strep. mutans. 
Table 2. Presence of streptomycin-resistant Strep. mutans in saliva samples in relation to persistence of the microorganisms on tooth surfaces

\begin{tabular}{|c|c|c|c|c|c|c|c|}
\hline \multirow[b]{2}{*}{ Subject } & & \multicolumn{6}{|c|}{ Weeks after removal of the artificial fissure } \\
\hline & & $1-4$ & $4-8$ & $8-12$ & $12-16$ & $16-20$ & $20-26$ \\
\hline \multirow[t]{2}{*}{ G } & $\begin{array}{l}\text { No. of tooth } \\
\text { surfaces colonized }\end{array}$ & 2 & 0 & 0 & ND + & $\mathrm{ND} \ddagger$ & 0 \\
\hline & $\begin{array}{l}\text { Per oent saliva samples } \\
\text { positive }\end{array}$ & 27 & 14 & 4 & $29^{*}$ & 0 & ND \\
\hline \multirow[t]{2}{*}{$\mathrm{T}$} & $\begin{array}{l}\text { No. of tooth } \\
\text { surfaces colonized }\end{array}$ & 10 & 7 & 8 & ND & ND & 0 \\
\hline & $\begin{array}{l}\text { Per cent saliva samples } \\
\text { positive }\end{array}$ & 19 & 29 & 40 & $14 \dagger$ & 2 & 0 \\
\hline \multirow[t]{2}{*}{$\mathbf{S}$} & $\begin{array}{l}\text { No. of tooth } \\
\text { surfaces colonized }\end{array}$ & 20 & 14 & 4 & ND & ND & 6 \\
\hline & $\begin{array}{l}\text { Per cent saliva samples } \\
\text { positive }\end{array}$ & 45 & $41 \dagger$ & 24 & 39 & 72 & 32 \\
\hline
\end{tabular}

* 1 lump of sugar every waking hour for 11 days.

$\dagger$ Daily fluoride rinses.

$\ddagger$ Not determined.

for strain $G$. Subject $G$ was then placed on a high sugar regimen in which he ate a lump of sugar every waking hour for 11 days. Twenty nine per cent of his salivary samples became positive for the streptomycin-resistant strain. When the frequent sucrose ingestion was stopped, no streptomycin-resistant Strep. mutans strains were detected in his salivary samples. At the end of the experiment, at week 26 , no tooth surfaces were positive for strain $G$. In subjects $T$ and $S$, daily fluoride rinses, i.e. $5 \mathrm{ml}$ of 0.4 per cent stannous fluoride and $5 \mathrm{ml}$ of 0.02 per cent acidulated phosphate fluoride (Iradicy ${ }^{\otimes}$, Janar Co., Grand Rapids, Mich.), were administered for a 4-week period in order to eliminate or reduce the implanted strain. In subject $\mathrm{T}$, the implanted Strep. mutans strain was present in 40 per cent of the salivary samples prior to rinsing, but decreased to 14 per cent during rinsing and was not detectable in either the saliva or on the tooth surfaces at week 26 (Table 2). In subject $S$ the fluoride rinsing did not eliminate the implanted strain, as both saliva and some tooth samples remained positive during the whole experimental period. The positive salivary samples in all subjects were due to low levels of the implanted strain, i.e. $\leq 10^{3} / \mathrm{ml}$.
After the establishment of strain $S$ on adjacent and anlagonistic tooth surfaces in subject $S$, a sterile AF was inserted on multiple occasions into the molar site. These AFs were removed at various time intervals and the ratio of streptomycin-resistant CFUs of Strep. mutans to total Strep. mutans was determined for the $\mathrm{AF}$ and for the saliva at the time of the removal of the AF. After 1 day, approximately 90 per cent of the Strep. mutans in the AF were streptomycin resistant, whereas onlv 0.1 per cent of the Stren. mutans in the saliva were resistant to streptomycin (Table 3 ). At 2, 5 and 21 days, the proportions of streptomycin-resistant strains decreased in the AF, but these proportions were always at least 100 -fold higher than the corresponding ratio of these organisms in the saliva.

\section{DISCUSSION}

In all subjects, the intraoral spread of the implanted Strep. mutans occurred only on the same side of the dentition as that on which the implantations were made. The extent of the intraoral spread varied widely in the three test persons, which may be due to a variety of host, diet and microflora factors. The dissimilarity of the hosts is illustrated by their different caries

Table 3. Colonization of sterile artificial fissures (AF) by Strep. mutans

\begin{tabular}{|c|c|c|c|c|}
\hline \multicolumn{5}{|c|}{$\begin{array}{l}\% \text { Streptomycin-resistant Strep. mutans of total } \\
\text { Strep. mutans CFU count in AF and in saliva }\end{array}$} \\
\hline $\begin{array}{l}\text { Days after } \\
\text { insertion } \\
\text { of AF }\end{array}$ & & $\begin{array}{l}\mathrm{AF} \\
\text { per cent }\end{array}$ & & iva \\
\hline $\begin{array}{r}1 \\
2 \\
5 \\
21\end{array}$ & $\begin{array}{l}n=2 \\
n=2 \\
n=3 \\
n=1\end{array}$ & $\begin{array}{l}87.0,90.0 \\
93.5,10.7 \\
33.0,10.7,10.5 \\
11.5\end{array}$ & $\begin{array}{l}n=6 \\
n=10 \\
n=33 \\
n=16\end{array}$ & $\begin{aligned} \text { ave }= & 0.1 \\
& 0.1 \\
& 0.1 \\
& 0.004\end{aligned}$ \\
\hline & \multicolumn{2}{|c|}{ Range $10.5-93.5$ per cent } & \multicolumn{2}{|c|}{$0.0-1.5$ per cent } \\
\hline
\end{tabular}


experience, number of retention sites such as margins of fillings and salivary Strep. mutans concentrations. Subject $S$ had a high number of filled tooth surfaces and a high salivary concentration of endogenous Strep. mutans strains, i.e. $10^{6} \mathrm{CFU}$ per $\mathrm{ml}$ (Svanberg and Loesche, 1978). Subject $G$ had a lower caries experience and a low salivary concentration of endogenous Strep. mutans strains, i.e. about $10^{3}$ CFU per $\mathrm{ml}$, and subject $\mathrm{T}$ was intermediate in regards to the various parameters under discussion (Svanberg and Loesche, 1978).

The importance of dietary sucrose in raising the salivary concentrations of the implanted Strep. mutans was demonstrated in subject $G$, when this subject went on a dietary regimen of frequent sucrose ingestion. The implanted strain $G$, which had been undetected in 24 consecutive salivary samples, re-emerged in the salivary flora, showing that a person can be a carrier of Strep. mutans at undetectable levels in plaque samples collected from tooth surfaces using dental floss and sharp needles, as well as in saliva samples. This finding confirms earlier observations (Svanberg and Loesche, 1978) that a Strep. mutansinfected retention site, such as an AF, often may remain undetected by the sampling techniques at present available.

The implanted Strep. mutans strains spread to adjacent and antagonistic tooth surfaces. The spread was detected only on the side of the dentition where the implantations were made, confirming the observations of Fdman et al. (1975). This suggests that the number of streptomycin-resistant CFU of Strep. mutans shed from the AF is so low that they become diluted in the saliva so that their chance to make contact with teeth on the other side of the dentition is slight. We have shown (Svanberg and Loesche, 1978) that AFs containing more than $10^{5} \mathrm{CFU}$ of the labelled Strep. mutans shed $10^{2}-10^{3} \mathrm{CFU}$ of these organisms per $\mathrm{ml}$ of saliva. The saliva contains about $10^{8} \mathrm{CFU}$ of various bacteria per $\mathrm{ml}$, which means that in homogenized whole saliva about one in every 100,000 to $1,000,000$ organisms would be of the labelled strain. Homogenized whole saliva, however, is an artifact of our culturing procedure. In vivo, the saliva flowing over the side containing the AF would be enriched for the streptomycin-resistant strains, whereas the saliva flowing over the opposite side would most likely have no streptomycin-resistant strains. The higher salivary concentrations of Strep. mutans on the implanted side would favour unilateral spread of the labelled organisms. This was so when sterile AFs were inserted in subject $S$ after the establishment of the implanted Strep. mutans on adjacent and antagonistic teeth. The local spread of Strep. mutans strains was illustrated by the relationship between the percentage streptomycin-resistant Strep. mutans of total Strep. mutans CFU counts in the AF, i.e. 10.5-93.5 per cent and in the salivary flora, i.e. 0.0-1.5 per cent. The salivary concentrations of the implanted Strep, mutans were on all occasions lower than those found previously to be associated with Strep. mutans colonization of a sterile AF (Svanberg and Loesche, 1978) and of a smooth tooth surface (van Houte and Greene, 1974). The shedding of Strep. mutans strains from infected areas probably increases the local salivary concentrations to such an extent compared to whole saliva that colonization of adjacent and antagonistic teeth is favoured. It is, however, also possible that contact between teeth greatly enhances the spread of Strep. mutans strains.

In all subjects, all tooth surfaces that harboured the implanted Strep. mutans strains were also colonized by streptomycin-sensitive strains of Strep. mutans. The streptomycin-sensitive Strep. mutans were presumably of endogenous origin, as the streptomycin-resistant marker is stable in vivo (Svanberg and Loesche, 1978). This indicates that strains $G, T$ and $S$ coexisted for a time with the endogenous strains of Strep. mutans.

Acknowledgements-This work was supported by U.S. Public Health Grants Nos. DE-02731, DE-03011 and DE-03423 from the National Institute of Dental Research. Dr. Thorkild Karring generously provided some of the AFs.

\section{REFERENCES}

Edman D. C., Keene H. J., Shklair I. L. and Hoerman K. C. 1975. Dental floss for implantation and sampling of Streptococcus mutans from approximal surfaces of human teeth. Archs oral Biol. 20, 145-148.

Gold O. G., Jordan H. V. and van Houte I. 1973. A selective medium for Streptococcus mutans. Archs oral Biol. 18, 1357-1364.

Grenier E. M., Eveland W. C. and Loesche W. J. 1973. Identification of Streptococcus mutans serotypes in dental plaque by fluorescent antibody techniques. Archs oral Biol. 18, 707-715.

Jordan H. V., Englander H. R., Engler W. A. and Kulcyzk S. 1972. Observations on the implantation and transmission of Streptococcus mutans in humans. J. dent. Res. 51, 515-518.

Keyes P. H. 1962. Recent advances in dental caries research. Bact. Int. dent. J. 12, 443-448.

Keyes P. H. and Fitzgerald R. J, 1962. Dental caries in the Syrian hamster IX. Archs oral Biol. 7, 267-278.

Keyes P. H. 1968. Research in dental caries. J. Am. dent. Ass. 76, 1357-1373.

Krasse B., Edwardsson S., Svensson I. and Trell L. 1967. Implantation of caries inducing streptococci in the human oral cavity. Archs oral Biol. 12, 231-236.

Krasse B., Jordan H. V., Edwardsson S., Svensson I. and Trell L. 1968. The occurrence of certain "caries-inducing" streptococci in human dental plaque material. Archs oral Biol. 13, 911-918.

Löe H., Karring T. and Theilade E. 1973. An in vivo method for the study of the microbiology of occlusal fissures. Caries Res. 7, 120-129.

Loesche W. J., Rowan J., Straffon L. H. and Loos P. J. 1975. Association of Streptococcus mutans with human dental decay. Infect Immun. 11, 1252-1260.

Shklair I. L. and Keene H. J. 1974. A biochemical scheme for the separation of the five varieties of Streptococcus mutans. Archs oral Biol. 19, 1079-1081.

Svanberg M. and Loesche W. J. 1977. Salivary concentrations of Streptococcus mutans and Streptococcus sanguis and the colonization of artificial fissures in man by these organisms. Archs oral Biol. 22, 441-447.

Svanberg M. and Loesche W. J. 1978. Implantation of Streptococcus mutans on tooth surfaces in man. Archs oral Biol. 23, 551-556.

Syed S. A. and Loesche W. J. 1972. Survival of human dental plaque flora in various transport media. Appl. Microbiol. 24, 638-644. 
Syed S. A. and Loesche W, J. 1973. Efficiency of various growth media in recovering oral bacterial flora from human dental plaque. Appl. Microbiol. 26, 459-465. van Houte J. and Green D. B. 1974. Relationship between the concentration of bacteria in saliva and the colonization of teeth in humans. Infect. Immun. 9, 624 630. 